\title{
Was Asian Rice (Oryza sativa) Domesticated More Than Once?
}

\author{
Duncan A. Vaughan • Bao-Rong Lu • Norihiko Tomooka
}

Received: 1 May 2008 / Accepted: 18 June 2008/Published online: 29 August 2008

(C) Springer Science + Business Media, LLC 2008

\begin{abstract}
Recently, a dual or multiple origin of domesticated rice has been the prevailing opinion among rice scientists because rice is clearly differentiated into two major varietal groups, indica and japonica, and several minor groups. Molecular clock studies that suggested that divergence in the A-genome wild rice genepool occurred prior to domestication gave further weight to the opinion that rice had a dual origin. However, recent analysis of the major gene that is responsible for the difference in degree of shattering between rice and wild rice has revealed that it is the same mutation in indica and japonica rice, which is not compatible with a dual origin of domesticated rice. Here, we discuss the geographic and genetic reasons why a single origin for domesticated rice is compatible with current data regarding the evolution of rice. The apparently conflicting data regarding the origin of rice can be resolved by the role hybridisation-introgression has played during rice evolution since domestication.
\end{abstract}

Keywords Origin · Evolution · Gene flow · Introgression . Hybridisation

\footnotetext{
D. A. Vaughan $(\bowtie) \cdot N$. Tomooka

National Institute of Agrobiological Sciences,

2-1-2 Kannondai,

Tsukuba 305-8602 Ibaraki, Japan

e-mail: Duncan@affrc.go.jp

B.-R. $\mathrm{Lu}$

Ministry of Education Key Laboratory for Biodiversity Science and Ecological Engineering, Institute of Biodiversity Science, Fudan University,

Shanghai 200433, China
}

\section{Introduction}

We have recently argued, contrary to the prevailing current opinion, that rice was only domesticated once [76]. This was based primarily on the following facts that: (1) the two main rice varietal groups, indica and japonica, have the same major allele for non-shattering [37]; (2) the absence of archaeobotanical evidence for two areas of domestication [16]; (3) the lack of evidence to support wild rice with indica- and japonica-like characteristics occurring in different geographic regions [61]; and (4) evidence that indica and japonica domesticated rice have the same time span since domestication [8].

The hypothesis that we proposed differs from views expressed in most recent papers on the subject of rice domestication (e.g. $[29,32,38,69])$ in two principal ways. First, we consider there is a lack of evidence that rice was domesticated in two different geographic regions, South Asia and East Asia. Secondly, we consider it unlikely that rice was domesticated twice prior to the spread of the principal allele for non-shattering in rice.

Thirty years ago, a single origin of rice was the commonly held opinion [10, 49]. However, molecular studies have shown that there are deep genetic divisions in cultivated rice $[12,19]$ and that some of these divisions appear to extend back in time before rice was domesticated $[41,56,79,88]$. As a result, the view has changed, and currently, a diphyletic or multiphyletic origin of domesticated rice in Asia is the prevalent opinion among rice scientists.

In this paper, we look at the geographic and genetic evidence that supports a single origin of domesticated rice and discuss the evolutionary process of hybridisationintrogression that may reconcile the apparently conflicting data related to the origin of domesticated rice in Asia. 


\section{Cultivation versus domestication}

Cultivation is a human activity, while domestication is a process that leads to genetic changes [18]. Plants cultivated by man may result in them changing genetically in response to the environment created by man, a part of the domestication process. However, if the genetic changes associated with cultivation do not result in the plants becoming dependent on man for survival, the plants are not domesticated. Some plants long harvested and cultivated by humans have failed or been difficult to domesticate; for example, American wild rice (Zizania aquatica), which is not an aggressive colonizer of disturbed habitats [28].

During the domestication process, a point is reached when sufficient genetic change has occurred for plants to become dependent on humans for survival at which point they are domesticated. For cereals, most botanists consider non-shattering to be the key change associated with domestication (e.g. [87]). Once a crop is domesticated, the process of domestication continues, and the various secondary traits associated with the domestication syndrome continue to accumulate.

\section{Geography of rice domestication}

'The history of the earth is recorded in the layers of its crust; the history of all organisms is inscribed in the chromosomes' Kihara, 1946 (quoted by [13]). Unlike the history written on the Earth's crust, chromosomes cannot tell us where the history of organisms occurred.

Vavilov [74] believed that centers of diversity of crops were a reliable indicator of where they originated. Thus, for a long period, it was believed that rice originated where it has traditionally been most diverse [10]. However, diversity in landraces often involves introgression from wild relatives (e.g. [6, 9]). This can lead to false conclusions regarding varietal diversity and the origin of crops [5]. The earliest archaeological sites that have domesticated rice remains are well outside the region where highest traditional varietal diversity was found in the last century, Yunnan province, China and surrounding areas.

Indica-japonica trend in wild rice

Genome-wide evidence for the early divergence of the Asian wild rice genepool comes from studies of insertion and divergence of long terminal repeat (LTR) retrotransposons [41, 79]. Based on molecular clock data, this divergence occurred long before domestication of rice and corresponds to germplasm that today is indica and japonica. The full meaning of LTR retrotransposons in terms of what is understood as indica and japonica differentiation is unclear. It is perhaps noteworthy that these papers used very limited germplasm to represent indica and japonica genepools. For example, of the 32 japonica accessions analyzed by [79], all came from Korea and Japan, and only one indica accession came from China. However, putting the validity of using DNA fragments for indica-japonica differentiation aside, does this pre-domestication divergence of the A-genome wild rice genepool equate to geographic differentiation as has been suggested [79]? Various studies using different techniques show clearly that wild rice germplasm with indica- and japonica-like profiles are found in the same region [47, 62, 67, 83]. Xu et al. [83] analysed $p$-SINE1 variation in wild and cultivated rice and showed that among perennial wild rice that tend to be japonica-like were two accessions, one from China and the other from Indonesia. They also showed that two perennial wild rice accessions that were more indica-like came from China and India [83]. An extensive isozyme analysis of wild and cultivated rice revealed that Chinese wild rice was of two groups [62]. One group of wild rice accessions, from Kwangsi, had similar isozyme alleles to those found in japonica rice. The other group of wild accessions from Guangdong province were intermediate between indica and japonica rice [62]. Wild germplasm from South and Southeast Asia in that study were only of the intermediate type.

Various studies have shown the tendency for indica-like characteristics to be associated with annual type wild rice and japonica-like characteristics to be associated with perennial type wild rice (e.g. [47, 83, 84]). Annual and perennial wild rice in various parts of Asia can be found in the same area [33] and sometimes at the same site as part of a contiguous population ([33]; first author's personal observations in Cambodia, India and Myanmar). The type of gradation in wild rice populations that can be found at some sites is illustrated (Fig. 1).

Indica-japonica trend in cultivated rice

The geographic basis for the names of the two main subgroups of rice varieties, indica and japonica, suggests correctly that this is therefore where these varieties are grown. This reflects the general trend that indica rice varieties are grown in tropical and subtropical regions of low latitude and low altitude with warmer climatic conditions and japonica in high altitudes or temperate regions of high latitudes with cooler climatic conditions. However, the names indica and japonica were not designated because of where these varietal groups originated, rather as a result of studies of hybrid fertility relationships [30]. Indica and japonica cultivated rice can be found sympatric in many areas. Indica varieties are grown in Japan for cattle forage. In mountainous regions such as 
Fig. 1 Continuum of plant types that can be found in some parts of South and Southeast Asia (modified from [75]).

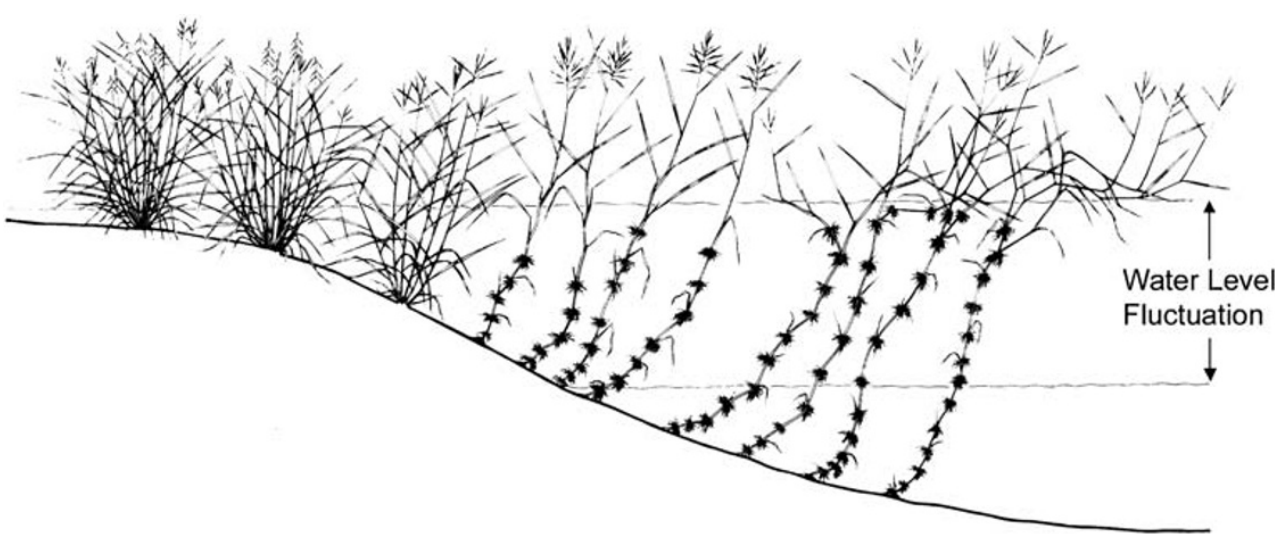

Bhutan, Nepal and Yunnan Province, China, indica varieties are grown at lower elevations and japonica at higher elevations. Sometimes, japonica and indica varieties are found in the same field [45] or same village [78] (Table 1). The occurrence of indica and japonica rice in the same or different places is largely due to human-mediated movement of rice varieties. This is clearly illustrated with the introduction of tropical japonica varieties during the Indonesian expansion to Madagascar and subsequent introduction of indica varieties from South Asia [77]. A consequence of these waves of introductions of rice into Madagascar was inter-subspecific (indica/japonica) hybridisation that has resulted in a varietal group specific to Madagascar [1].

Table 1 Rice Varietal Diversity Collected in Two Villages in Northwest Vietnam in October 1989

\begin{tabular}{|c|c|c|c|}
\hline Variety name & Culture type & Variety group & Amylose \% \\
\hline \multicolumn{4}{|l|}{ Ethnic Group: Thai } \\
\hline \multicolumn{4}{|c|}{ Village: Muong Pon, altitude $450 \mathrm{~m}$} \\
\hline Tu Vong & Upland & Japonica & 2 \\
\hline Khao Pit & Upland & Japonica & 2 \\
\hline Khao Lech & Upland & Japonica & 3 \\
\hline Khao lep Trong & Upland & Japonica & 2 \\
\hline Khao Coi Noi & Upland & Japonica & 2 \\
\hline $\mathrm{Pu}$ Loah & Upland & Indica & 2 \\
\hline Khao Coi Loi & Upland & Japonica & 3 \\
\hline Khao Pen Tien & Upland & Japonica & 4 \\
\hline Khao Tu Rong & Rainfed & Japonica & 2 \\
\hline Khao Ten Lai & Rainfed & Japonica & 1 \\
\hline \multicolumn{4}{|c|}{ Ethnic group: Humong } \\
\hline \multicolumn{4}{|c|}{ Village: Sothan, altitude $1,175 \mathrm{~m}$} \\
\hline Blau Ta & Upland & Japonica & 21 \\
\hline Blau La & Rainfed & Indica & 26 \\
\hline Ble Blau & Rainfed & Indica & 3 \\
\hline Blau Tan & Upland & Japonica & 3 \\
\hline Blau Blau & Rainfed & Japonica & 1 \\
\hline Talenoi & Rainfed & Indica & 17 \\
\hline Blau Bla & Rainfed & $\mathrm{Nc}$ & 1 \\
\hline
\end{tabular}

The two villages were $130 \mathrm{~km}$ apart.
The areas where traditional varieties of indica and japonica rice grew in China in the early part of the last century are shown (Fig. 2). The recent principal area of distribution of indica and japonica varieties in China is significant because this is the main area in the lowlands where indica and japonica rice shows a transition. Is it coincidental that this is close to where the first evidence of rice domestication has been reported?

Archaeobotanical evidence for different areas of rice domestication

There is clear archaeobotanical evidence that rice was domesticated by between 5000 and 4000 B.C. in the Yangtze River basin [17, 18, 85]. There is no equivalent evidence that rice was domesticated in South Asia or elsewhere in Asia [16]. While tropical climates are not considered conducive to conserve archaeobotanical remains, there is clear archaeobotanical evidence for the domestication of several crops in South Asia such as black and green gram (Vigna mungo and Vigna radiata) [17]. The archaeological data for the Ganges River basin reveals that sedentary agricultural villages were established after 2500 B.C. [16]. Earlier dates regarding the nature of human occupation at archaeological sites and the actual status of rice from early periods are unclear [16].

Several authors (e.g. $[3,14])$ have argued that migration of people from China into northeastern India brought languages and other elements of culture that might have included crop domesticates. Among crops of Chinese origin that appears early, before 2000 B.C., in South Asian agriculture is common foxtail millet (Setaria italica) [15]. It is difficult to deduce if domesticated rice was also introduced from China since wild rice was abundant and at least harvested and possibly cultivated in early Neolithic times in South Asia [27]. Since domesticated foxtail millet was introduced at an early date from China to South Asia, it is likely other crops, including domesticated rice, were also introduced. 
Fig. 2 The traditional areas where indica and japonica varieties were grown in the midtwentieth century (based on [71].

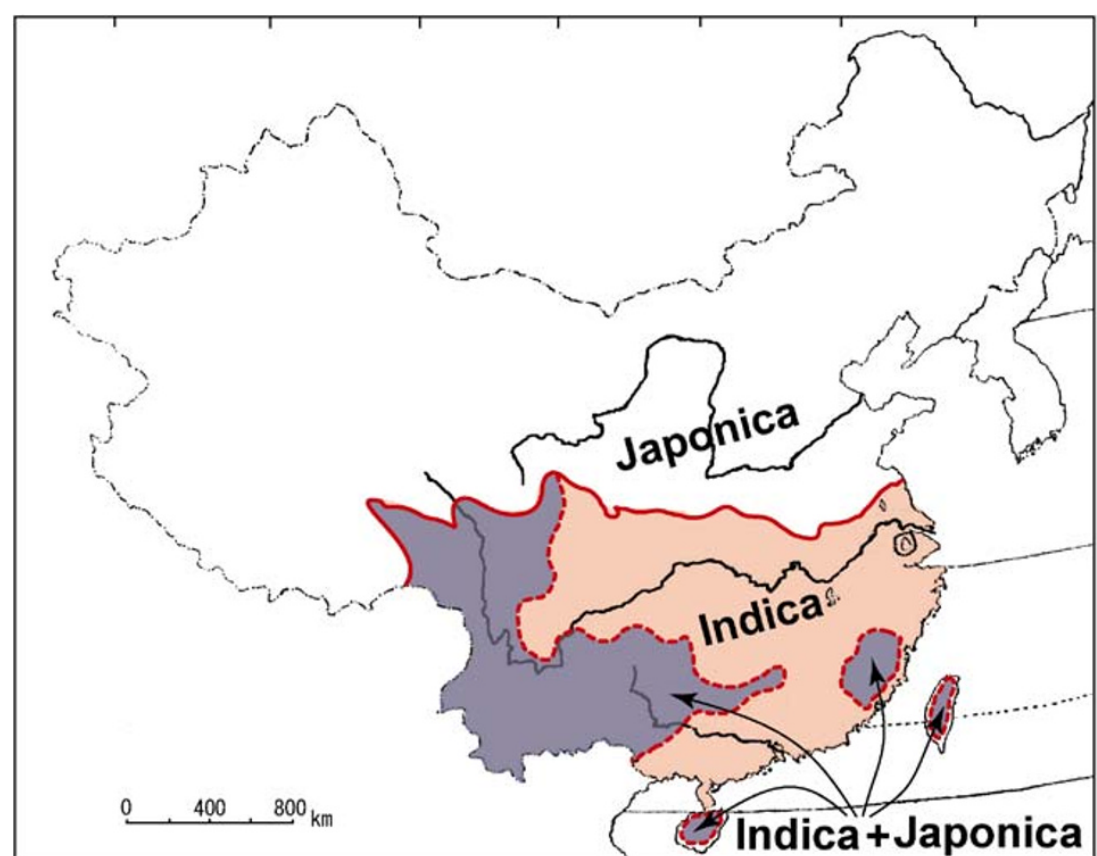

Domesticated rice was introduced from China into other parts of Asia, such as the Philippines. Based on the dates for the appearance of domesticated rice in the Yangtze River basin, the time that people migrated from this region to other parts of Asia and lack of conclusive archaeobotanical evidence for early-domesticated rice in South Asia, it seems probable that the first domesticated rice in South Asia came from China.

\section{People and rice migration}

At the time rice was being domesticated in China, who were the people living in the Yangtze River region? It is thought that three of the major Asian linguistic groups originate in the general area of the Yangtze River, the SinoTibetan, Hmong-Mien and Tai [4]. Although precise information is not available about where these different linguistic groups originated, it is clear that, in the region rice was first domesticated, there was human diversity that resulted in distinct human linguistic lineages. This human diversity may have hastened the early diversification of rice. Different ethnic groups have different preferences for rice taste and texture, as the rice diversity in different villages in northeast Vietnam illustrates (Table 1).

People, crops and technology can spread more rapidly east and west than north and south. Crops require time to adapt to different day lengths associated with change in latitude. The Ganges-Brahmaputra Rivers at about $25^{\circ} \mathrm{N}$ is about as far south as the Yellow River $\left( \pm 35^{\circ} \mathrm{N}\right)$ is north of the Yangtze River $\left( \pm 30^{\circ} \mathrm{N}\right)$. This is a relatively small span of latitudes and would not have taken many generations for domesticated rice to adapt to latitudes of the Indo-Gangetic plain given that wild rice genetic resources were (and are) abundant there. In contrast, spread of rice across insular Asia, through the Philippines to Indonesia, in excess of $30^{\circ}$ latitude spread where wild rice is not so abundant, would have been a much slower process.

\section{Genetics of domestication in rice}

Genetics of indica-japonica differentiation in wild rice

The predominant and ancient divergence in Asian rice is between indica and japonica varieties. The difference in these two types of domesticated rice was recognised as long ago as the second century A.D. (Han dynasty) in China [71]. At both the phenotypic and molecular level, the distinction between these two types of rice is clear [46]. Significant genetic differentiation has resulted in strong reproductive barriers between the extreme types of indica and japonica. Consequently, there are different levels of sterility between the two varietal groups, particularly $F_{2}$ sterility and $F_{2}$ weakness [49].

The main axes of genetic variation in wild rice are related to habitat adaptation and geography. Wild rice populations adapted to permanently wet habitats are mainly outcrossing and perennial, known as Oryza rufipogon, that is widely distributed from southern China and South Asia through Southeast Asia to the northern part of Australia [75]. Wild rice populations adapted to seasonally dry/wet habitats are predominantly inbreeding and annual. Often, this type of wild rice is called Oryza nivara. Variation is continuous between these two types [48] (Fig. 1). In 
addition to ecotypic differentiation, wild rice shows geographic variation due to isolation by distance [39, 62].

Studies to determine if indica and japonica traits exist in the wild genepool have examined phenotypic traits [47], isozymes [47, 61, 62], molecular markers [7, 12, 67, 83, 84, 86] and DNA sequences [88]. Twenty-three morphological and physiological traits, that discriminate perennial and annual habit and indica and japonica characteristics, all showed continuous variation in 65 strains of wild rice [47]. Principle component analysis showed a trend towards indica/japonica-like differentiation, but this was not well developed. Molecular studies have also shown that japonica and indica characteristics are found in different types of wild rice [83, 84]. Population genetic studies of 86 indica, 53 japonica varieties, and 11 O. rufipogon populations using microsatellite (SSR) markers showed considerable association of $O$. rufipogon individuals from different populations within an area or individuals in the same population with either indica or japonica varieties [67]. The insertion/deletion (InDel) molecular markers, developed from BLAST of the total genomic sequences between the typical indica (93-11) and japonica (Nipponbare), showed a certain degree of genetic differentiation in the O. rufipogon complex including $O$. rufipogon, $O$. nivara and weedy rice at some InDel loci $[7,86]$. Thus, wild rice shows cryptic variation related to indica and japonica differentiation that is fully expressed in cultivated rice.

From these studies, one reason for the presence of traits associated with indica/japonica differentiation in wild rice is hybridisation-introgression between cultivated rice (either indica or japonica) and wild rice $[7,67,86]$. Hybridisationintrogression representing the gene flow between cultivated rice and wild rice has been widely observed in nature and proven by designed field experiments [11, 40, 64, 65]. Wild rice occurs only in tropical lowlands, whereas indica and japonica rice cultivars are usually associated with cultivation at different altitudes or latitudes. Further understanding of why there is apparently a pre-domestication tendency towards indica and japonica differentiation in wild rice is needed as this might shed light on the origin and diversification of domesticated rice.

\section{Genetics of rice domestication traits}

It has been argued that the domestication of cereals was a slow process, and this implies a long period of harvesting wild stands and then cultivation prior to cereals becoming fully domesticated $[18,70,81]$. During the period prior to full domestication, undoubtedly there was selection of genes that suit plants to the cultivated environment. There are many genes or quantitative trait locus (QTL) associated with the major domestication traits. Based on various studies for shattering, there are at least ten loci on eight of the 12 rice chromosomes, and for dormancy, there are at least 25 loci on ten chromosomes (summarised by [78]). Most of these genes have small overall effect.

\section{Shattering}

The main QTL (qSH1) that distinguishes the degree of shattering between indica and japonica varieties explains $69 \%$ of the difference in these two groups of non-shattering rice [31]. Non-shattering alleles at some shattering loci are present in Japanese weedy rice [73]. Weedy rice differs in the degree of shattering, but all weedy rice readily shed their seeds either naturally like wild rice or at a slight touch during the harvesting of rice. Therefore, some degree of non-shattering is not a condition that a plant is a domesticate. Only non-shattering that prevents seeds easily falling prior to harvest can be considered a feature of a domesticated cereal. In rice, there is only one known gene that significantly $(>50 \%)$ prevents shattering and that gene is sh4 [36]. Analysis of this non-shattering allele in 96 indica varieties and 112 japonica varieties has shown that this allele is the same in both varietal groups [37].

It has been shown that the two main QTLs associated with shattering are epistatic [54]. One QTL $(q S H 1)$ is associated with abscission layer formation, and the other, $\operatorname{sh} 4$, is associated with abscission process. Since $\operatorname{sh} 4$ is the result of the same mutation in indica and japonica rice, this mutation must have preceded mutation and divergence at the qSH1 locus that distinguishes the ease of shattering between these varietal groups. Another shattering-related QTL, qSH3, is also epistatic to $q S H 1$ and $s h 4$, and the interaction among QTLs associated with shattering may explain the complexity found in the genetics of shattering in weedy rice [73].

\section{Dormancy}

Dormancy is a complex trait consisting of seed and hull dormancy. Progress in understanding the detailed genetics of this trait in rice has lagged that for shattering. Secondary dormancy remains an important characteristic in indica varieties, where seeds retain viability during hot, humid conditions between planting seasons. The most detailed studies of dormancy have been conducted with an accession of wild-like weedy rice from Thailand (accession SS18-2) that exhibits hull-imposed dormancy [21-26]. The most important dormancy-related QTL in this Thai accession was located on chromosome 12 , explaining about $50 \%$ of the phenotypic variance $[22,24]$. This chromosome 12 QTL may be the most important to study in relation to rice domestication because reduced dormancy must have been selected for early in the process of domestication. If this major dormancy QTL on chromosome 12 is widespread in 
the rice genepool, when it is cloned [22], it may be as informative as the shattering QTL sh4 has been regarding rice domestication.

\section{Hybridisation-introgression and its probable role in rice domestication}

How can the pre-domestication indica/japonica tendency in wild rice be compatible with a single origin of domesticated rice that is strongly suggested by a single major nonshattering allele in the two varietal groups? The only reasonable explanation appears to be the important role of hybridisation-introgression in the evolutionary process of rice after it was domesticated.

Hybridisation-introgression is the permanent incorporation of genes from one set of differentiated populations into another [59]. Introgression is more likely to occur in young species [42] or populations that have recently diverged in which reproductive barriers have not developed or are weak. While mutation is the ultimate source of genetic variation [55], it has been argued that this alone is insufficient to provide the variation to permit major evolutionary advances [68]. The importance of 'mass hybridisation between populations with different adaptive norms' [68], recombination [20] and introgression [2] have been stressed as sources of genetic variation in the evolution of plant genomes.

The genepool of an emerging domesticate is one where selection results in populations with different adaptive norms in proximity, with weak, if any, barriers to gene exchange. Hybridisation is a prerequisite for introgression. In Asia, most hybrids between rice and wild rice with the A-genome are fertile and have normal chromosome pairing at meiosis [53]. Thus, the A-genome taxa of Oryza in Asia form a single biological species [43] with populations adapted to various ecological conditions in close proximity that allow hybridisation-introgression to occur.

The environment of early agriculture would have provided the ecological conditions that are thought to promote introgressive hybridisation-highly disturbed habitats such as those resulting from human activity [59].

The role of different domestication-related mutations in the origin of rice has been investigated in detail (discussed above). However, the role of introgression in the origin and diversification of rice is poorly understood, particularly with respect to the evolutionary fitness of genotypes resulting from introgression. There have been various studies that have provided evidence of introgression in the genepool of rice. Early studies documented introgression based on morphological characteristics and isozymes [35, $48,50-52,57,61]$. These studies have established that introgression occurs in the genepool of rice. These studies have also shown that introgression can result in new ecotypes [35], increased genetic diversity [35, 51] and the transfer of adaptations $[35,50]$.

Recently, there have been many studies of gene flow and hybridisation-introgression between crops (including rice) and their wild relatives due to concerns related to transgene escape from genetically modified crops. Consequently, a large amount of data relating to gene flow from cultivated rice to its weedy and wild relatives have been generated $[11,64,65,63,80]$. These studies showed that the frequency of gene flow from cultivated rice to $O$. rufipogon varied between $1 \%$ and $18 \%$ in one generation and from cultivated rice to weedy rice between $0.01 \%$ and $0.5 \%$ in one generation. Further studies have demonstrated that the introgressed crop traits can persist in wild rice populations and results in further impact on wild rice populations ([66]; B.R. Lu et al. unpublished). These studies highlight the frequent gene exchange between cultivated rice and its wild relatives over a long time span and the importance of cropweedy-wild introgression in the evolutionary process of cultivated rice, as well as wild rice [67]. The potential gene flow has played in explaining variation in rice has been suggested from a recent survey of genome-wide patterns of nucleotide polymorphism [8]. Data from that same study also suggested 'that equal timing of domestication (for indica and tropical japonica) is likely to have occurred' [8].

A recurrent problem with the studying populations of wild rice in Asia today is that it is difficult to know the extent to which long-term gene flow from domesticated rice affects the population genetic structure of wild rice. It is known that many populations of Asian wild rice have introgressed genes from cultivated rice [7, 34, 65, 86]. Among wild rice accessions for which bacterial artificial chromosome libraries are available [82], at least one accession appears to have introgressed genes from cultivated rice. This accession [International Rice Research Institute (IRRI) 105491] from Malaysia has been studied in detail, and among its characteristics are upright habit and bold grains that point to introgression from cultivated rice [44]. Another famous wild rice accession, O. nivara from India (IRRI 101508), that furnished grassy stunt virus resistance to modern rice cultivars, also exhibits signs of introgression as it has straw colored hull like cultivated but not wild rice.

To understand the origin of domesticated rice, it is necessary to have a clearer idea of the variation that existed in the wild rice genepool in the Yangtze River basin 7,000 years ago. It is also necessary to design experiments to further elucidate the role of hybridisation-introgression during the evolution of domesticated rice into its presentday diversity.

The difficulties of unravelling the role of hybridisationintrogression in crop evolution are probably a major reason 
that its significance has not been fully appreciated in the evolution of rice. Currently, vast rice and wild rice genomic resources are becoming available for rice and wild rice [72]. These resources should enable it to be easier to detect and quantify hybridisation-introgression [58] and its role in the evolution of rice to be resolved.

\section{Conclusions}

Based on information currently available, neither geography nor genetics of rice and wild rice exclude the possibility that rice was only domesticated once. The fact that the key domestication allele for non-shattering is the same in varieties of indica and japonica rice tested to date means that a single domestication of rice, at least for the major varietal groups, was not just possible but probable.

It is not difficult to believe that during the period after the emergence of the first domesticated rice there would have been an abundance of cultivated (semi-cultivated) and wild rice occurring in close vicinity. Gene flow among different forms of rice (cultivated, semi-cultivated and wild) would have made the genetic structure of these populations 'messy'. Subsequent gene flow among domesticated, semidomesticated and wild rice would have started the process of introgression. A feature of this environment must have been populations with high genetic variation from which early farmers selected different types of rice. Therefore, hybridisation-introgression between cultivated and wild rice has occurred since the onset of rice domestication. This process, together with farmers' selection, has resulted in the great diversification of cultivated rice genepool. The indica- or japonica-associated alleles found in wild rice are most likely the result of hybridisation-introgression of indica or japonica cultivars with wild rice.

\section{References}

1. Ahmadi N, Glaszmann JC, Radary E. Traditional highlands rices originating from intersubspecific recombination in Madagascar. In Rice Genetics II, International Rice Research Institute, 67-79, P.O. Box 933, Manila, Philippines, 1991.

2. Anderson E. Introgressive hybridisation. New York: Wiley; 1949.

3. Bellwood P. The origins and spread of agriculture in the IndoPacific region: gradualism and diffusion or revolution. In: Harris DR, editor. The origins and spread of agriculture and pastoralism in Eurasia. London: UCL Press; 1996. p. 465-98.

4. Bellwood P. Asian farming diasporas? Agriculture, languages and genes in China and Southeast Asia. In: Stark MT, editor. Archaeology in Asia. Oxford: Blackwell; 2006. p. 96-118.

5. Burger JC, Chapman MA, Burke JM. Molecular insights into the evolution of crop plants. Am J Bot 2008;95:113-22.

6. Burke JM, Knape SJ, Rieseberg LH. Genetic consequences of selection during the evolution of cultivated sunflower. Genetics 2005;171:1933-40.
7. Cai XX, Liu J, Qiu YQ, Zhao W, Song ZP, Lu B-R. Differentiation of Indica-Japonica rice revealed by insertion/ deletion (InDel) fragments obtained from the comparative genomic study of DNA sequences between 93-11 (Indica) and Nipponbare (Japonica). Front Biol China 2007;2(3):291-6.

8. Caicedo AL, Williamson SH, Hernandez RD, Boyko A, FiedelAlon A, York TL, et al. Genome-wide patterns of nucleotide polymorphism in domesticated rice. Plos Genet 2007;3:1745-56.

9. Casa AM, Mitchell SE, Hamblin MT, Sun H, Bowers JE, Paterson $\mathrm{AH}$, Aquadro CF, Kresovich S. Diversity and selection in sorghum: simultaneous analyses using simple sequence repeats. Theor Appl Genet 2005;111:23-30.

10. Chang TT. Crop history and genetic conservation: rice- a case study. Iowa State J Res 1985;59:425-55.

11. Chen LJ, Lee DS, Song ZP, Suh HS, Lu B-R. Gene flow from cultivated rice (Oryza sativa) to its weedy and wild relatives. Ann Bot 2004;93:67-73.

12. Cheng C, Motohashi R, Tsuchimoto S, Fukuta Y, Ohtsubo H, Ohtsubo E. Polyphyletic origin of cultivated rice: based on the interspersion pattern of SINEs. Mol Biol Evol 2003;20: 67-75.

13. Crow JE. Hitoshi Kihara, Japan's pioneer geneticist. Genetics 1994;137:891-4.

14. Diamond J, Bellwood P. Farmers and their languages: first expansions. Science 2003;300:597-603.

15. Fuller DQ. An agricultural perspective on Dravidian historical linguistics: archaeological crop packages, livestock and Dravidian crop vocabulary. In: Bellwood P, Renfrew C, editors. Examining the farming/language dispersal hypothesis. Cambridge: Macdonald Institute Monographs; 2003. p. 191-213.

16. Fuller DQ. Agricultural origins and frontiers in South Asia: a working synthesis. J World Prehist 2006;20:1-86.

17. Fuller DQ. Contrasting patterns in crop domestication and domestication rates: recent archaeological insights from the Old World. Ann Bot 2007;100:903-24.

18. Fuller DQ, Harvey E, Qin L. Presumed domestication? Evidence for wild rice cultivation and domestication in the fifth millennium BC of the Lower Yangtze region. Antiquity 2007;81:316-31.

19. Garris AJ, Tai TH, Coburn J, Kresovich S, McCouch SR. Genetic structure and diversity in Oryza sativa L. Genetics 2005;169: 1631-8.

20. Gaut BS, Wright SI, Rizzon C, Dvorak J, Anderson LK. Recombination: an underappreciated factor in the evolution of plant genomes. Nat Rev Genet 2007;8:77-3.

21. Gu X-Y, Chen Z-X, Foley ME. Inheritance of seed dormancy in weedy rice. Crop Sci 2003;43:835-43.

22. Gu X-Y, Kianian SF, Foley ME. Multiple loci and epistases control genetic variation for seed dormancy in weedy rice (Oryza sativa). Genetics 2004;166:1503-16.

23. Gu X-Y, Kianian SF, Foley ME. Phenotypic selection for dormancy introduced a set of adaptive haplotypes from weedy into cultivated rice. Genetics 2005a; 171:695-704.

24. Gu X-Y, Kianian SF, Hareland GA, Hoffer BL, Foley ME. Genetic analysis of adaptive syndromes interrelated with seed dormancy in weedy rice (Oryza sativa). Theor Appl Genet 2005b;110:1108-18.

25. Gu X-Y, Kianian SF, Foley ME. Isolation of three dormancy QTLs as Mendelian factors in rice. Heredity 2006a;96:93-9.

26. Gu X-Y, Kianian SF, Foley ME. Dormancy genes from weedy rice respond divergently to seed development environments. Genetics 2006b;172:1199-211.

27. Harvey EL, Fuller D, Pal JN, Gupta MC. Early agriculture of the Neolithic Vindhyas (North-Central, India). Proceedings of the European Association for South Asian Archaeology Conference, Bonn, Germany, 7-11 July, 2003. pp 329-334. Aachen: Linden Soft, 2005. 
28. Hayes PM, Stucker RE, Wandrey GG. The domestication of American wildrice (Zizania palustris, Poaceae). Econ Bot 1989;43:203-14.

29. Kawakami S, Ebana K, Nishikawa T, Sato YI, Vaughan DA, Kadowaki K. Genetic variation in the chloroplast genome suggests multiple domestication of cultivated Asian rice (Oryza sativa L.). Genome 2007;50:180-7.

30. Kato $\mathrm{S}$, Kosaka $\mathrm{H}$, Hara $\mathrm{S}$. On the affinity of rice varieties as shown by fertility of hybrid plants. Bull. Sci Fac. Agric. Kyushu Univ., Fukuoka, Japan 1928;3:132-47.

31. Konishi S, Izawa T, Lin S-Y, Ebana K, Fukuta Y, Sasaki T, et al. An SNP caused loss of seed shattering during rice domestication. Science 2006;312:1392-6.

32. Kovach MJ, Sweeney MT, McCouch SR. New insights into the history of rice domestication. Trends Genet 2007;23:578-87.

33. Kuroda Y, Urairong H, Sato YI. Differential heterosis in a natural population of Asian wild rice (Oryza rufipogon Griff.) due to reproductive strategy and edge effect. Genet Resour Crop Evol 2005;52:151-60.

34. Kuroda Y, Sato YI, Bounphanousay C, Kono Y, Tanaka K. Genetic structure of three Oryza AA genome species $(O$. rufipogon, $O$. nivara and $O$. sativa) as assessed by SSR analysis on the Vientiane Plain of Laos. Conservation Genetics 2007;8:149-58.

35. Langevin SA, Clay K, Grace JB. The incidence and effects of hybridization between cultivated rice and its related weed red rice (Oryza sativa L.). Evolution 1990;44:1000-8.

36. Li C, Zhou A, Sang T. Rice domestication by reduced shattering. Science 2006;311:1936-9.

37. Lin Z, Griffith ME, Li X, Zhu Z, Tan L, Fu Y, et al. Origin of seed shattering in rice (Oryza sativa L.). Planta 2007;226:11-20.

38. Londo JP, Chiang YC, Hung KH, Cheng TY, Schaal B. Phylogeography of Asian wild rice reveals multiple independent domestications of cultivated rice, Oryza sativa. Proc Natl Acad Sci U S A 2006;103:9578-83.

39. Lu B-R, Zheng KL, Qian HR, Zhuang JY. Genetic differentiation of wild relatives of rice as referred by the RFLP analysis. Theor Appl Genet 2002;106:101-6.

40. Lu B-R, Snow AA. Gene flow from genetically modified rice and its environmental consequences. BioScience 2005;55:669-78.

41. Ma J, Bennetzen JL. Rapid recent growth and divergence of rice nuclear genomes. Proc Natl Acad Sci U S A 2004;101:12404-10.

42. Mallet J. Hybridization as an invasion of the genome. Trends Ecol Evol 2005;20:229-37.

43. Mayr E. The species problem. American Association for the Advancement of Science Publication No. 50; 1957.

44. McCouch SR, Sweeney M, Li J, Jiang H, Thomson M, Septinginsih E, Edwards J, Moncada P, Xiao J, Garris A, Tai T, Martinez C, Tohme J, Sugiono M, McClung A, Yuan LP, Ahn SN. Through the genetic bottleneck: $O$. rufipogon as a source of traitenhancing alleles for O. sativa. Euphytica 2007;154:317-39.

45. Morishima H. Intra-population genetic diversity in landrace of rice. Proc. Of the 6th Internatl. Congr. of SABRAO; 1989.

46. Morishima $\mathrm{H}$. Conservation and genetic characterization of plant genetic resources. Pages 31-42 in MAFF International Workshop on Genetic Resources. National Institute of Agrobiological Resources, Tsukuba, Japan; 1998.

47. Morishima H, Gabrinab LU. Are the Asian common wild rices differentiated into the indica and japonica types. Pages 11-20 in Crop exploration and utilization of genetic resources. Proceedings of International Symposium held at Changhua, Taiwan; 1987.

48. Morishima H, Oka HI, Chang WT. Directions of differentiation in populations of wild rice, Oryza perennis and $O$. sativa $\mathrm{f}$. spontanea. Evolution 1961;15:326-39.

49. Oka HI. Origin of cultivated rice. Amsterdam: Elsevier; 1988. p. $1-254$.
50. Oka HI, Chang WT. The impact of cultivation on populations of wild rice, Oryza sativa f. spontanea. Phyton 1959;13:105-17.

51. Oka HI, Chang WT. Hybrid swarms between wild and cultivated rice species, Oryza perennis and O. sativa. Evolution 1961;15: 418-30.

52. Oka HI, Morishima H. The impact of plant domestication: cultivation experiments with Oryza and its hybrid with Oryza sativa. Evolution 1971;25:356-64.

53. Ogawa T. Genome research in genus Oryza. In: Nanda JS, Sharma SD, editors. Monograph on Genus Oryza. Science Publishers, Inc. Enfield, New Hampshire, USA; 2003. p. 171-212.

54. Onishi K, Takagi K, Kontani M, Tanaka T, Sano Y. Different patterns of genealogical relationships found in the two major QTLs causing the loss of seed shattering during rice domestication. Genome 2007:50:756-66.

55. Pickersgill B, Heiser CB. Cytogenetics and evolutionary change under domestication. Philos Trans R Soc Lond B 1976;275: $55-69$.

56. Rakshit S, Rakshit A, Matsumura H, Takahashi Y, Hasegawa Y, Ito A, et al. Large-scale DNA polymorphism study of Oryza sativa and $O$. rufipogon reveals the origin and divergence of Asian rice. Theor Appl Genet 2007;114:731-43.

57. Richard P. Coping with hunger: hazard and experiment in an African rice-farming system. UK: Allen and Unwin; 1986.

58. Rieseberg LH. The role of hybridisation in evolution: old wine in new skins. Am J Bot 1995;82:944-53.

59. Rieseberg LH, Wendel JF. Introgression and its consequences in plants. In: Harrison RG, editor. Hybrid zones and evolutionary processes. Oxford: Oxford University Press; 1993. p. 70-109.

60. Rong J, Xia H, Zhu Y, Wang Y, Lu BR. Asymmetric gene flow between traditional and hybrid rice varieties (Oryza sativa) indicated by nuclear simple sequence repeats and implications for germplasm conservation. New Phytol 2004;163:439-45.

61. Second G. Origin of the genic diversity of cultivated rice (Oryza spp.): study of the polymorphism scored at 40 isozyme loci. Jpn J Genet 1982;57:25-57.

62. Second G. Evolutionary relationships in the Sativa group of Oryza based on isozyme data. Genet Sel Evol 1985;17:89-114.

63. Shivrain VK, Burgos NR, Anders MM, Rajguru SN, Moore J, Sales MA. Gene flow between Clearfieldä rice and red rice. Crop Prot 2007;26:349-56.

64. Song ZP, Lu B-R, Zhu YG, Chen JK. Pollen competition between cultivated and wild rice species (Oryza sativa and O. rufipogon). New Phytol 2002;253:289-96.

65. Song ZP, Lu B-R, Zhu YG, Chen JK. Gene flow from cultivated rice to the wild species Oryza rufipogon under experimental field conditions. New Phytol 2003;157:657-65.

66. Song ZP, Lu B-R, Wang B, Chen JK. Fitness estimation through performance comparison of $\mathrm{F}_{1}$ hybrids with their parental species Oryza rufipogon and O. sativa. Ann Bot 2004;93:311-6.

67. Song Z, Zhu W, Rong J, Xu X, Chen J, Lu B-R. Evidences of introgression from cultivated rice to Oryza rufipogon (Poaceae) populations based on SSR fingerprinting: implications for wild rice differentiation and conservation. Evol Ecol 2006;20: 501-22.

68. Stebbins GL. The role of hybridisation in evolution. Proc Am Philos Soc 1959;103:231-51.

69. Sweeney M, McCouch SR. The complex history of the rice domestication. Ann Bot 2007;100:951-7.

70. Tanno KL, Willcox G. How fast was wild wheat domesticated? Science 2006;311:1886.

71. Ting Y. Chronological studies of the cultivation and distribution of rice varieties keng and sen (in Chinese). Sun Yatsen University Agronomy Bulletin 1949;6:1-32.

72. Upadhyaya NM (editor) 2007. Rice functional genomics: Challenges, progress and prospects. New York: Springer. 
73. Ushiki J, Akasaka M, Watanabe H, Vaughan D. Weedy rice (Oryza sativa L.) evolution in Japan as a model for comparative international studies of weedy rice. 5th International Weed Science Congress Vancouver, Canada, June; 2008.

74. Vavilov NI. Studies on the origin of cultivated plants. Institut Botanique Applique et Amelioration des Plantes, State Press, Leningrad, USSR; 1926.

75. Vaughan DA. The wild relatives of rice. Los Banos, Philippines: IRRI; 1994.

76. Vaughan DA, Lu BR, Tomooka N. The evolving story of rice evolution. Plant Sci 2008;174:394-408.

77. Vaughan DA, Miyazaki S, Miyashita K. The rice genepool and human migrations. In: Werner D, editor. Biological resources and migration. Berlin: Springer; 2004. p. 1-11.

78. Vaughan DA, Sanchez PL, Ushiki J, Kaga A, Tomooka N. Asian rice and weedy rice - evolutionary perspectives. In: Gressel J, editor. Crop ferality and volunteerism. Baco Raton: Taylor \& Francis; 2005. p. 257-77.

79. Vitte C, Ishii T, Lamy F, Brar D, Panaud O. Genomic paleontology provides evidence for two distinct origins of Asian rice (Oryza sativa L.). Mol Gen Genomics 2004;272:504-11.

80. Wang F, Yuan QH, Shi L, Qian Q, Liu WG, Kuang BG, Zeng DL, Liao YL, Cao B, Jia SR. A large-scale field study of transgene flow from cultivated rice (Oryza sativa) to common wild rice $(O$. rufipogon) and barnyard grass (Echinochloa crusgalli). Plant Biotechnol J 2006;4:667-76.
81. Weiss E, Kislev ME, Hartmann A. Autonomous cultivation before domestication. Science 2006;312:1608-10.

82. Wing RA, Ammiraju JS, Luo M, Kim H, Yu Y, Kudrna D, Goicoechea JL, et al. The Oryza map alignment project: the golden path to unlocking the genetic potential of wild rice species. Plant Mol Biol 2005;59:53-62.

83. $\mathrm{Xu} \mathrm{J-H}$, Cheng $\mathrm{C}$, Tsuchimoto $\mathrm{S}$, Ohtsubo $\mathrm{H}$, Ohtsubo E. Phylogenetic analysis of Oryza rufipogon strains and their relations to Oryza sativa strains by insertion polymorphism of rice SINEs. Genes Genet Syst 2007;82:217-29.

84. Yamanaka S, Nakamura I, Nakai H, Sato YI. Dual origin of the cultivated rice based on molecular markers of newly collected annual and perennial strains of wild rice species, Oryza nivara and O. rufipogon. Genet Resour Crop Evol 2003;50:529-38.

85. Zheng YF, Sun GP, Chen XG. Characteristics of the short rachillae of rice from archaeological sites dating to 7000 years ago. Chin Sci Bull 2007;52:1654-60.

86. Zhao W, Xia HB, Zhang SJ, Cai XX, Lu B-R. Differentiation of Oryza species revealed by the Indica-Japonica specified insertion/ deletion (InDel) molecular markers. Journal of Fudan University (Natural Science), (in press); 2008.

87. Zohary D, Hopf M. Domestication of plants in the Old World. 3rd ed. Oxford: Oxford University Press; 2000.

88. Zhu Q, Ge S. Phylogenetic relationships among A-genome species of the genus Oryza revealed by intron sequences of four nuclear genes. New Phytol 2005;167:249-67. 